loss"; and it concludes, "If we American scientists wish to avoid a similar fate, if we wish to see the world continue to progress and prosper, we must bend our efforts to that end now."

The action of American men of science in issuing this manifesto on the relation of development in the international situation to the progress of science has fallen at a singularly opportune moment ; and its implications will not escape the notice of their colleagues in the countries of Europe. Unquestionably it has been to the advantage of the intellectual advancement of the world at large that, while in the political sphere the United States of America has held fast to isolation as a corollary of the Monroe Doctrine-a policy now for the second time within the present century under public consideration in view of danger to democratic institutions-that isolation has not been a characteristic of this great people in matters of the spirit, more especially in the development of the arts and in science. By free exchange and interchange of ideas and personnel, the New World has co-operated with the Old to their mutual benefit; while the recent approach of the American Association for the Advancement of Science to the British Association, for the promotion of joint consideration and discussion of problems of scientific import and socio-economic application, opens up further prospects of an accelerated movement towards world unity in attack on those broader questions in which science touches the interests and well-being of mankind as a whole. Notwithstanding differences in social conditions between the United States and the countries of the Old World, which would militate against either the utility, or perhaps even the possibility, of like action in the very different circumstances prevailing in the European democracies, nevertheless the pronouncement of American men of science inculcates a principle in its statement of the relation of scientific progress and democratic institutions, which may well be laid to heart ; and it is of no less importance that once more it has demonstrated in practical form the essential solidarity of the world of science.

\title{
The Census and the Distribution of Population
}

$\mathrm{E}$ VERY civilized community needs a full and accurate knowledge of its human resources; and bence the census has developed far beyond its primary function of merely numbering the people. It has become a periodic stocktaking; and among other aims it should provide precise and full information about the distribution of the people within a country.

Every person is counted at the place in which he, or she, is at the date of the census. This gives the first facts of the distribution, what is called the de facto population of each census district and of the country. In the past this has been considered sufficient, provided that the actual censua could be carried out within a very short time, so short that no appreciable movements took place during the count. Up to 1921 , it was the only distribution directly recorded by the census in Great Britain. But in that year the count was made in June, instead of in April as usual; and the holiday movements which had then begun caused serious uncertainties in the results as compared with those of other censuses and with intercensal estimates. Hence in 1931 there was introduced a question requiring each person to state his usual, or legal, place of residence.
This made it possible to count the regular inhabitants of each district, and so to measure the de jure population, by excluding visitors and including temporary absentees, a second stage in an accurate measure of distribution. The difference between the de facto and the de jure populations may at some places and times be considerable, especially in a holiday resort such as Blackpool ; and it is obviously necessary to know the numbers of the resident population for many purposes of administration. The counting of the de jure population has always been the aim of censuses taken to determine electoral constituencies, as in the United States of America; it is surprising that it did not come earlier in Great Britain.

The requirement that each person shall state his place of birth enables the census to obtain some information regarding the origins and migrations of the people it enumerates. It is regret. table that the separation of Eire from the United Kingdom in 1922 has been allowed to interrupt the continuity of the records under this head. This can be avoided for the future if under 'birthplace' in the schedule we write 'British Isles' in place of 'United Kingdom'; and so obtain records 
comparable with those of censuses before 1922, without losing anything in comparisons with that of 1931. A large part of the recent immigration into Great Britain is from Ireland; and fuller information about these immigrants is much to be desired.

In relation to the birthplace question, however, the chief desideratum is a fuller analysis and tabulation of the results. In 1931, for each administrative county and every town in England and Wales with more than 50,000 inhabitants, the census tables classed the numbers of those enumerated there into those born in that district, those born elsewhere in England, elsewhere in Wales, in Scotland, in Northern Ireland, or in any one of many other countries. But if the classification is to give information about migrations within England, 'elsewhere in England' is a useless grouping. To measure the 'drift to the south' it should be replaced by at least the county of birth of each person enumerated, for the whole of Great Britain or, preferably, for the British Isles. Also these migrants should be classified by age and sex, and perhaps also by occupations, so as to give a measure of the character of the migration. It is clear that to do this will involve much more detailed analysis and tabulation of the results. But the magnitude of the internal movements of our population has been so great in recent years, and its results are of such import. ance, as to justify a demand for the fuller and more precise knowledge of it which can only be obtained in this way.

Another important group of population movements is that of the daily journeys between residence and workplace. We all know that the day and night populations of many districts differ widely; but this knowledge is rarely precise. In 1921 the census schedule included a question on workplace, the answers to which gave valuable information on this daily ebb and flow of a large part of our population. The question was omitted in 1931 ; and only partly replaced by the requirement that each employee should state the address of his employer, which is usually the place at which he works. Thus, for 1931, this information is available for only a part of the population. The question should be restored for 1941, and applied to every person engaged in regular work. The importance of a knowledge of this daily movement for the planning of suburban transport, of roads, and of housing, and for other local government purposes, is quite obvious and sufficient to justify the cost involved in obtaining and tabulating the information.

Recent changes in the distribution of the population in Great Britain have been considerable. The 'drift to the south' (actually towards London and some parts of the Midlands), though it may have been exaggerated and misunderstood in the popular imagination, is a real and important fact. Such migrations, among a people whose numbers are no longer increasing to any considerable extent, involve actual decreases in the population of some other parts of the country. Before we can know the real importance of these movements or take any reasoned steps to deal with them, it is essential to have much more exact knowledge of their extent and range. In what numbers and in what proportions do the migrants come from the distressed areas, from highland areas, or from the rural areas and small towns? Do they spread themselves widely, or do they tend to move and settle in groups? There is urgent need for trustworthy answers to these and other questions concerning the migration; and a fuller analysis of the census returns can provide much material for the answers.

In England the census has provided from time to time, but never for all at the same time, information concerning four groups of facts relating to the distribution of the people. The first of these is the number of the de facto population of each census district at the time the census is taken. The second, begun only in 1931, is that of the de jure population, at its usual residence, for the same date. The third comes from the comparison of the first, or in future of the second, with the information as to birthplace, age, sex, and occupation; it gives a measure, necessarily incomplete but nevertheless of real value, of internal migrations and of immigration. The fourth group of facts relates to the daily, or other short-period, movements.

The importance of a knowledge of all these facts of distribution has been emphasized recently by considerations of air raid precautions and of civilian defence. A thorough knowledge of the normal distribution of the people is necessary for efficient defence in war, and not less so for any adequate national planning for times of peace. It is, therefore, very desirable that the coming census of 1941 should be used to obtain the fullest possible information about all four groups of facts relevant to the distribution of the population of Great Britain. 